\title{
Determination of the force required for the hydro- forming of al 99,5
}

\author{
Vasile Ceclan ${ }^{1, *}$, Sorin Grozav ${ }^{1}$ \\ ${ }^{1}$ Technical University of Cluj Napoca, Faculty of Machine Building, Blv Muncii 103-105, Cluj \\ Napoca, Romania
}

\begin{abstract}
In this paper the authors present the hydroforming of the tubular parts. It also presents the technology of the tubular parts' hydroforming. In this paper we determine the forces necessary for the hydroforming process. They are also presented the mechanical parameters of the material that are used in the deformation process. Also, the variation in wall thickness of the aluminium specimen is determined before the deformation process
\end{abstract}

Keywords: Hydroforming, Aluminium, Force, Wall thickness

\section{Introduction}

Hydroforming is a manufacturing process that uses the pressure exerted by a hydraulic medium to produce deformations of a sheet or tubular blank.

Tube hydroforming is a method commonly used in the manufacture of complex components in the automobile resistance structure and a manufacturing technology that is being assimilated in many other industrial sectors (aerospace, household goods).

Coordinating the internal pressure with the plunger axial feed is one of the basic requirements of the tube hydroforming process, which must ensure that there are no defects (breaking or breaking the walls).

The process of hydroforming the tubes with high internal pressure is one of the newest manufacturing processes for tubular components. Prior to hydroforming, the tubes may be performed. During hydroforming, the material is inflated by increasing the internal pressure by means of two plungers acting on the ends of the tube. The plungers perform the pressure of the tube heads by introducing the pressurized fluid through the plunger holes.

The advantage of this method of hydroforming consists in:

- the hydrostatic pressure of the liquid uniformly presses the preform using plunging, preventing the formation of creases, stretching and thinning of the processed material;

- the stress and deformation state is more favourable in the case of the hydroforming and it is possible to obtain parts in a single operation;

- the economic efficiency of the hydroforming process by introducing the pressure of liquid is more obvious and more productive than other classical processes deformation, since the deformation is accomplished in a single operation.

\footnotetext{
* Corresponding author: vasile.ceclan@tcm.utcluj.ro

Reviewers: Róbert Čep, Jozef Pilc
} 


\section{Calculations of pressure and forces required for hydroforming}

\subsection{Estimation of the hydroforming pressure}

The maximum pressure of the hydroforming fluid can be determined by the relationship Approximate [Singh, Neugebauer]:

$$
\mathrm{p}_{\max }=\mathrm{Rm} . \mathrm{s} / \mathrm{R}\left[\mathrm{N} / \mathrm{mm}^{2}\right] \text {, }
$$

Where: $\mathrm{Rm}=77.1 \mathrm{~N} / \mathrm{mm}^{2}$ is the maximum breaking strength of the material hydroformed (Al 99.5 ENAW 1050 H0 SR EN 10088-1: 2005);

$\mathrm{s}=1.5 \mathrm{~mm}$ - nominal wall thickness;

$\mathrm{R}=8 \mathrm{~mm}$ - the radius of connection of the vertical branch of the tube.

From the relation (1) results:

$$
p_{\max }=14.45 \mathrm{~N} / \mathrm{mm}^{2}=144.5 \text { bar. }
$$

Consider the approximate character of the formula (1). Numerical simulation of the hydroforming process will allow verification that this maximum value of pressure hydroforming allows complete connection.

\subsection{Determination of mould closing force}

The force of closing the mould (exerted by the press ram) must balance the effect mechanical pressure acting within the tubular blank. Considering the fact that, in the case of the hydroforming process, the internal pressure increases extremely rapidly at the level maximum, the ram force can be calculated using the relationship:

$$
\mathrm{F}_{\mathrm{ram}}=\mathrm{p}_{\max } \cdot 1_{\mathrm{sf}} \cdot \mathrm{d}_{\mathrm{sf}}=144.5 \cdot 99.5 \cdot 35=503221.21 \mathrm{~N}=503,22 \mathrm{KN} \text {. }
$$

The maximum pressure was multiplied by the area of the horizontal projection of the inner surface of the still unreformed blank.

\subsection{Determination of sealing force}

The sealing force (exerted by the plungers that axially press the ends of the emissive) performs a double function: plasticizing the material by bringing it closer to the tear strength, respectively balancing the opening effect of the pressure acting inside the tube. By summing the forces corresponding to the two axial plunger functions, the sealing force is obtained:

$$
\begin{aligned}
& \mathrm{F}_{\mathrm{s}}=\left[\pi(\mathrm{d}-\mathrm{s}) \cdot \mathrm{s} \cdot \mathrm{R}_{\mathrm{m}}\right]+\left[\mathrm{p}_{\max } \cdot \pi(\mathrm{d}-2 \mathrm{~s})^{2} / 4\right] \\
& \mathrm{F}_{\mathrm{s}}=[3,14 \cdot(35-1.5) \cdot 2 \cdot 77.1]+\left[144.5 \cdot 3,14 \cdot(35-2 \cdot 1.5)^{2} / 4\right]=117371,1 \mathrm{~N}=117,37 \mathrm{KN}
\end{aligned}
$$

In order to determine all these forces it was necessary to determine the parameters of the materials used in the actual hydroforming process.

\section{Experimental determinations of material parameters}

Figure 1 shows the state of stresses in the tube wall during the process and the following notations are inserted: $\mathrm{R}$ - outer tube radius, respectively $\mathrm{s}$ - thickness of the wall, $\sigma 1$ represents a circumferential stretching stress, and $\sigma 2$ - represents an axial compression stress.

The two non - zero voltage components in the tube wall are: negative and acts in the axial direction (corresponds to the compressive force F) and the other is positive and acts in the 
circumferential direction (represents the effect of the pressure stretching $p$ ). The hydroforming process is based, for example, on the swelling of a tubular blank, accompanied by axial or radial compression [1-7]. This process typically consists of the following steps: expansion with compression, calibration [5]. Hydroforming is part of the cold processing industry.

The process is used for the construction of highly complex geometry cavities from high deformability tubes or boards.

Table 1. Material Parameter of Al 99.5 ENAW 1050 H0

\begin{tabular}{|lc|}
\hline Parameter of material & Al 99,5 \\
\hline Tensile strength Rm & $77,1 \mathrm{MPa}$ \\
\hline Conventional Yield stress Rp0,2 & $58,9 \mathrm{MPa}$ \\
\hline Proportional elongation under maximum force Ag & $13,5 \%$ \\
\hline Total elongation below maximum force Agt & $18,7 \%$ \\
\hline
\end{tabular}

Figure 2 shows the curve of tension-percentage elongation for trial test of the material according to the standard SR EN 10002-1.

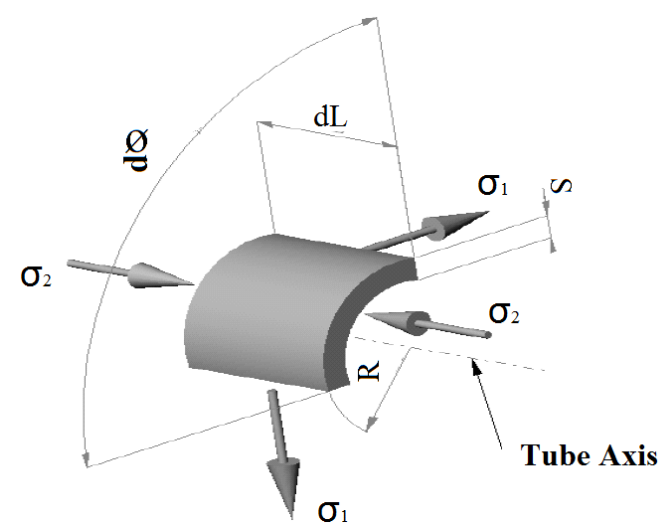

Fig. 1. The state of tension in the tube

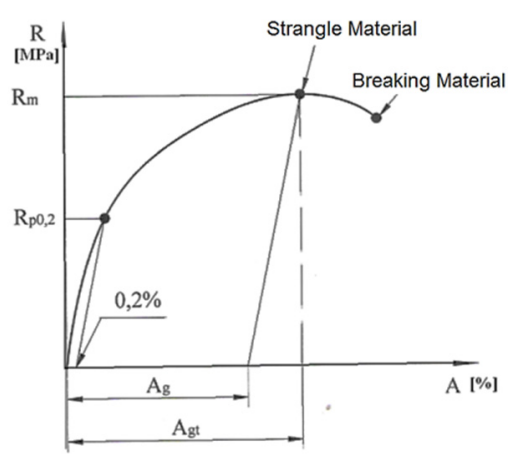

Fig. 2. Curve of tension-percentage elongation for traction test

One important fact on production of the tubular parts, it is the change of wall thickness. Because of the deformation and the tension inside of the material of the tubes, the parameters are change. On different specimens of aluminium tubes was scanned with very precis machine. Figure 3 it is present the variation of the wall thickness of aluminium AL 99.5 which was tested in this paper. This was measurement on 3D scanner with optical devises. The measurements of the specimens were performed in the same way they are presented by other authors $[8,9]$. In this figure it can be observed that it is a big variation of the thickness, between $1.46 \mathrm{~mm}$ and $1.58 \mathrm{~mm}$. The theoretical thickness must be $1.5 \mathrm{~mm}$. 


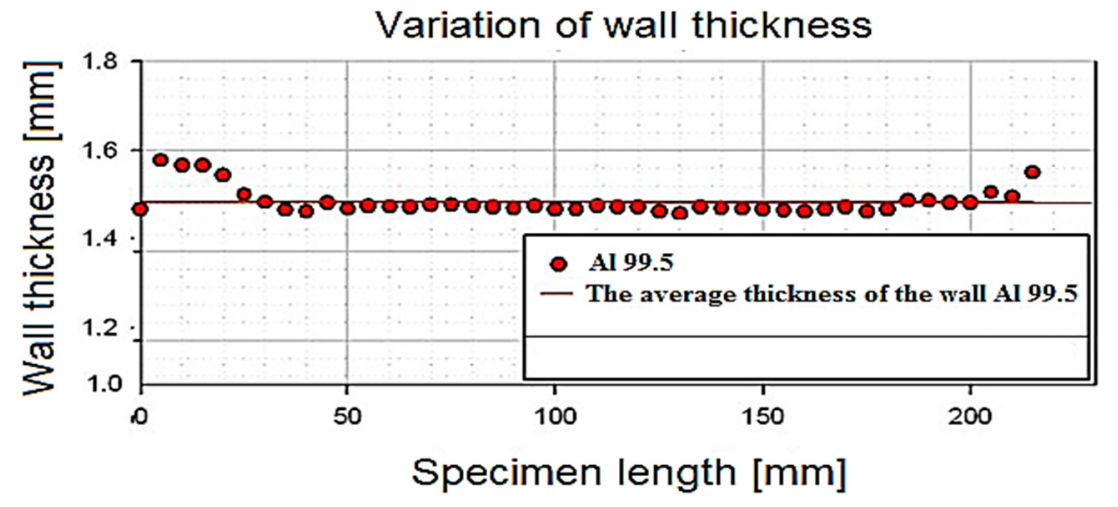

Fig. 3. Variation of wall thickness

These specimens were cut on the water jet machine OMAX, to don't be influenced by material parameters, because with this techniques the properties of mechanical parameter are not influenced [10-12].

The standard EN 10002-1: 1995 and EN 10002-2: 1995 show the shape and dimensions of the test specimens for uniaxial tensile strength.

After extracting these specimens, these were tested for uniaxial traction on machine Zwick - Roel Z150 which is in Technical University of Cluj-Napoca, as show in figure 4.

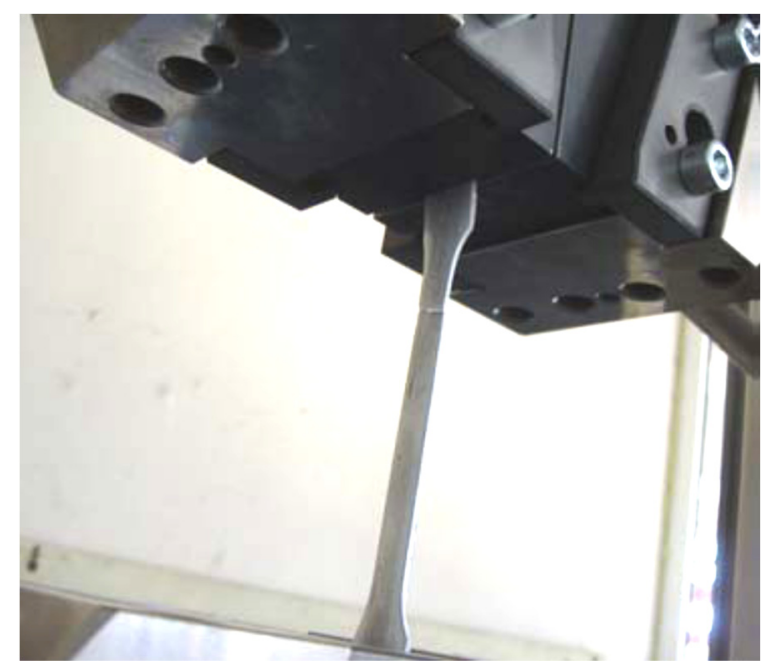

Fig. 4. Traction tests on the machine Zwick - Roel Z150.

To determine the mechanical properties characteristics it is good to make uniaxial tensile strength testing. This test involves the application of a tensile force on a specimen until fracture.

Figure 5 presents the stress-strain curves in the case of Al 99.5 ENAW 1050 H0 


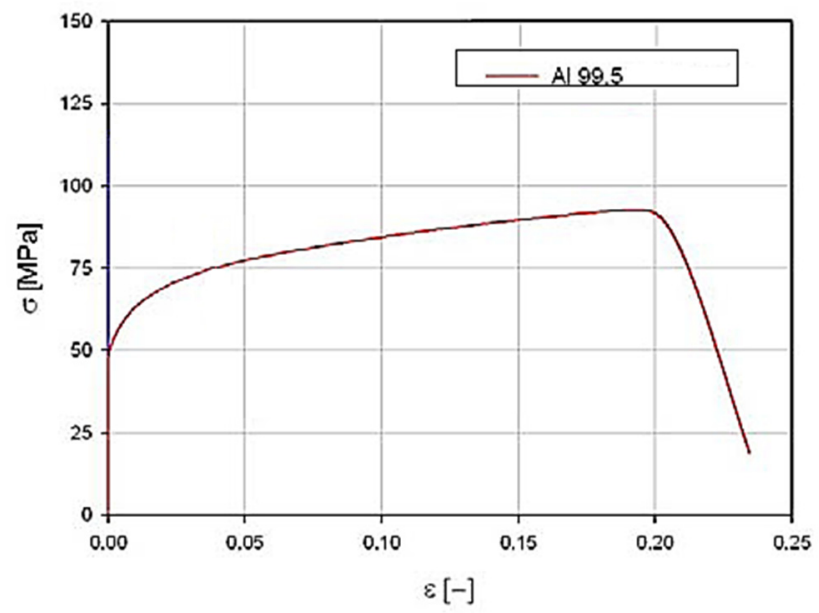

Fig. 5. Material curve for Al 99.5

\section{The own achievement of hydroforming}

In order to carry out the hydroforming process it was necessary to design and realize a deformation stand. This stand was made from: (1) - the hydroforming mould; (2) - hydraulic high pressure pump; (3) - Tinius - Olsen traction-compression test machine with rated force of $100 \mathrm{kN}$. In this stand it was necessary to control parameters of hydroforming.

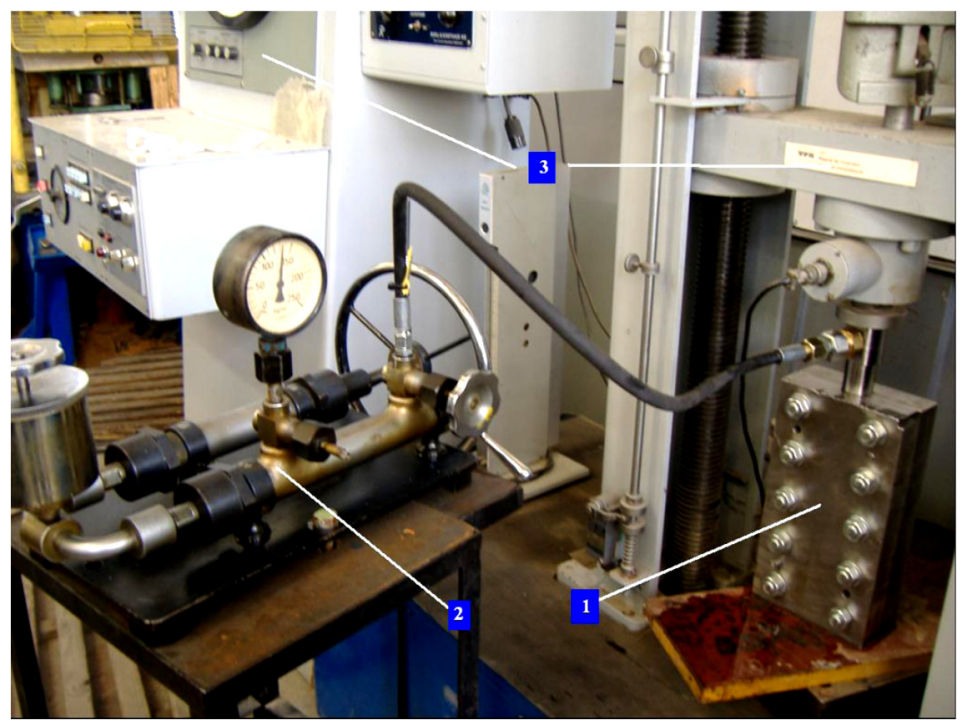

Fig. 6. Stand of hydroforming

In this stand it was necessary to control certain parameters. The most important parameters were the internal pressure of the liquid this was done by means of the pump ( 2 of figure 6). Another important parameter is the ram force; this can be controlled with the help Tinius - Olsen traction-compression test machine ( 3 of figure 6 ). The sealing force is given by the hydroforming mould ( 1 of figure 6 ). 


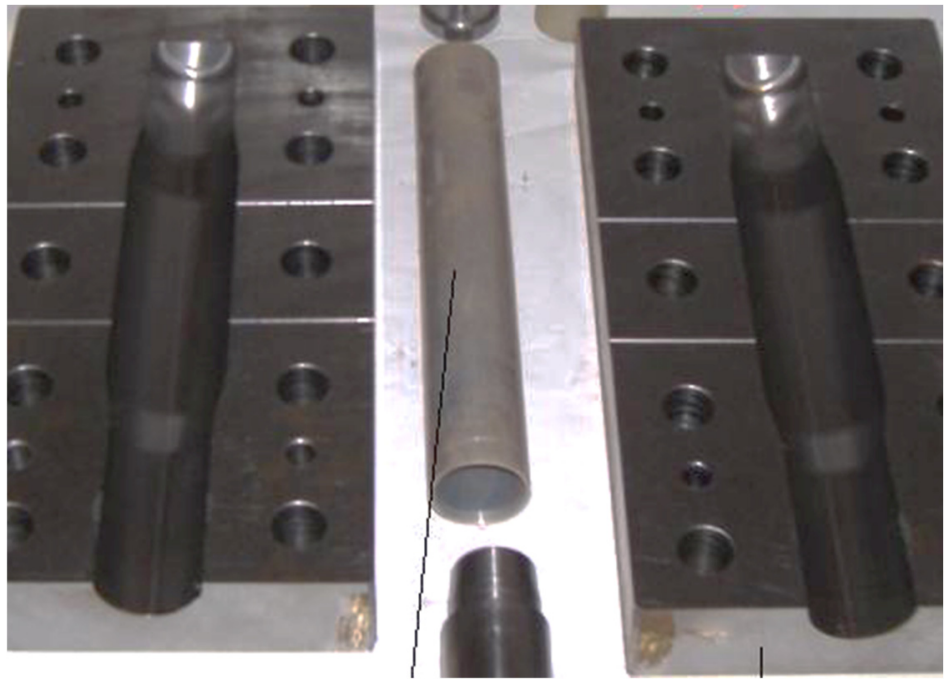

Fig. 7. Mould of hydroforming

The shape of the hydroforming mould is identical to the shape of the deformed tube. In figure 7 it is presented mould of hydroforming. This mould was made by CNC machine. [13$15]$

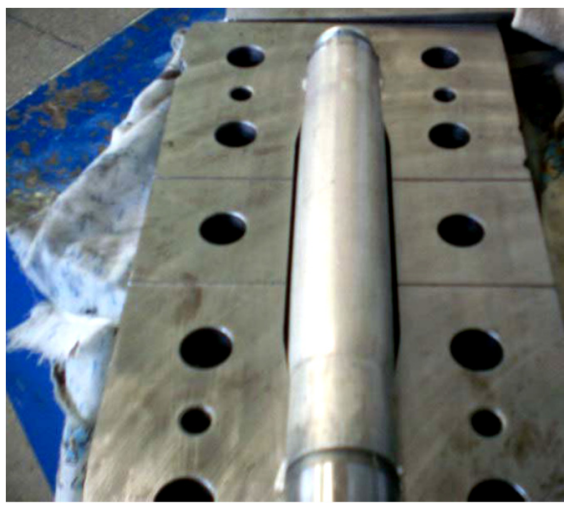

Fig. 8. Steps of hydroforming tubular part

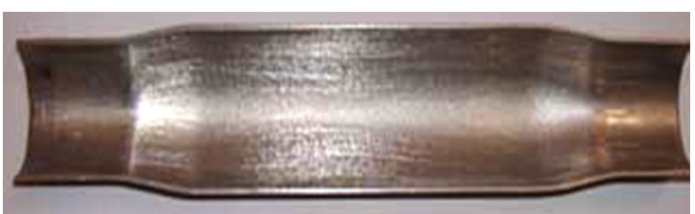

a)

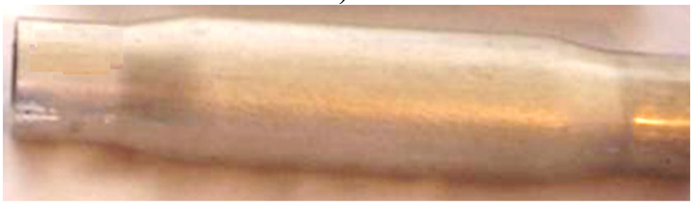

b)

Figure 8 shows the steps of the hydroforming process inside the mould. Hydraulic oil is used to deform the tubes. The specimen length was $220 \mathrm{~mm}$. It can be seen that depending on the shape of the mould, you get the shape of the hydro former tube, a procedure very similar to vacuum casting [16-18]. Figure 9 shows the tubes made by hydroforming. It is possible to observe the inner and outer surface of the tubes [19-21]. Figure 9a shows the difference in roughness caused by the hydroforming process. For the deformation process, tubes manufactured by the drawing process are suitable [22,23]. In figure $9 . \mathrm{b}$ it can be seen that the surface of the tube in the deformed area is better, also having a better roughness. 


\section{Conclusions}

This paper focused on the determination of the main factors influencing the hydroforming process of the tubular parts. The experiments in this paper focused on determining the main factors that influence the hydroforming process. Also took into account the quality of the tubular parts obtained.

As a result of the hydroforming process it can be observed that the obtained parts have much better strength and rigidity. Another effect of this process is to reduce the number of operations in order to obtain the finished piece, as well as to reduce its weight. Another important feature is the realization of complex shapes, and the optimal use of space. This process significantly reduces subsequent assembly operations. It is recommended to use hydraulic oil to reduce the friction forces between the piece and the die. After the laboratory tests, a theoretical model of calibration of the hydroforming process was made for different materials used. A great advantage of this simple device is that it is possible to install on universal cold pressing equipment.

This work was supported by a grant of the Romanian National Authority for Scientific Research and Innovation, CNCS/CCCDI-UEFISCDI, project number PN-III-P2-2.1-BG-2016-0216, within PNCDI III.

\section{References}

1. T. Jansson, Optimization of Sheet Metal Forming Processes. PhD thesis, Universitet Linkoping, Linkoping, Sweden (2002).

2. M. Jansson, Hydro-mechanical forming of aluminium tubes - On constitutive modelling and process design. PhD Thesis. Linkoping University (2006)

3. S, Jirathearanat, Advanced Methods for Finite Element Simulation for Part and Process Design in Tube Hydroforming. PhD Thesis. Ohio State University (2004)

4. J. Lunqvist, Numerical Simulation of Tube Hydroforming. Adaptive Loading Paths. Licentiate Thesis. Lulea University of Technology (2004)

5. Schuler Gmbh (ed.) Metal Forming Handbook. Berlin: Springer (1998)

6. K. Siegert, M. Haessermann, B. Losch, R. Rieger, Recent Developments in Hydroforming Tehnology. Journal of Materials Processing Technology 98, 251-258 (2000)

7. A. Szabo Ponce, Experimental Modeling and Control of Tube Hydroforming Process. MSc Thesis. University of Sao Paulo (2006)

8. L. Morovič and P. Pokorný, Optical 3D Scanning of Small Parts. Advanced Materials Research, Vols. 468-471, pp. 2269-2273 (2012)

9. J. Peterka et al., Optical 3D Scanning of Cutting Tools. Applied Mechanics and Materials, Vol. 421, pp. 663-667 (2013)

10. A. Popan et al., Research on Abrasive Water Jet Milling of the Planar Surfaces, Slots and Profiles. Applied Mechanics and Materials, Vol. 760, pp. 409-414 (2015)

11. A. Popan, N. Bâlc, I. Popan, Preliminary study on occurrence of composite material delamination processed by abrasive water jet cutting. MATEC Web of Conferences. EDP Sciences, 121, 02010 (2017) 
12. A. Popan, N. Balc, A. Carean, A. Luca, A. Miron, Research to improve the surface roughness of the parts made by water jet milling. AJME-2013, Vol. 11, Issue 2, $105-$ 109 (2013)

13. M.Sadílek, F. Fojtík, Z. Sadílková, K. Kolařík, J. Petrů, J. A Study of Effects of Changing the Position of the Tool Axis to the Machined Surface. Transaction of FAMENA, Vol. 39, No. 2, 33-46 (2015)

14. L. Kyncl, M. Sadílek, R. Čep, J. Petrů, D. Stanvekova, J. Procházka, P. Nováček, Tests of drills during drilling holes into alloy wheels. Manufacturing Technology, Vol. 14, No. 4, 554-561 (2014)

15. M. Sadílek, R. Čep, Z. Sadílková, J. Valíček, L. Petřkovská, Increasing tool life during turning with variable depth of cut. Materiali in tehnologije/Materials and technology. vol.47, no.2, 199-203 (2013)

16. A. Luca, N. Balc, I. Drstvensek, A. Popan, Analysis of aluminum parts for accuracy improvement in vacuumcasting process. Academic Journal of Manufacturing Engineering, Vol. IX, Issue 3, 75-80 (2011)

17. A. Luca, N. Balc, A. Popan, V. Ceclan, N. Panc, Improving the quality of the parts made by rapid metalcasting process. Academic Journal of Manufacturing Engineering, Vol. 12, Issue 1, 82-86 (2014)

18. A. Luca, N. Balc, A. Popan, N. Panc, The influence of investment casting process parameters of complex metal parts. Academic Journal of Manufacturing Engineering, Vol. 10, Issue 3, 57-62 (2012)

19. V.A. Ceclan et al. Quality of the hydroformed tubular parts. Advanced Engineering Forum 8-9: 215-224 (2013)

20. V. Ceclan, S.Grozav, E.Sabau, I. A. Popan, C. Borzan, Structural analysis of tubes hydroforming. Academic Journal of Manufacturing Engineering, Vol. 11, Issue 4, 56 59, (2013)

21. V. Ceclan, N. Balc, A. Miron, C. Borzan, I.A. Popan, Numerical simulation of the tube bending process and validation of the results. Academic Journal of Manufacturing Engineering, Vol. IX, Issue 3, 32-37 (2011)

22. Ridzoň M., The Effect of Technological Parameters Influencing the Properties of Seamless Cold-Drawn Tubes. - 1. ed. - (Hochschule Anhalt, Köthen). 89 (2012)

23. M. Ridzoň, L. Eleková, J. Lišková, J. Bílik: Effect of reduction in three-drawn and twodrawn single-run technology on roughness of inner surface of tubes, Volume 18, Number 28 (2010) 